\title{
Narrativas transmedia de no-ficción: Estudio de caso del podcast Le llamaban padre, de Carles Porta
}

\section{Fikziozkoak ez diren istorioen transmedia-narrazioa: Carles Portaren Le llamaban padre podcastaren kasu-azterketa}

\section{Non-fiction transmedia narratives: Case study of Carles Porta's podcast Le llamaban padre}

\section{Mariona Visa Barbosa ${ }^{1}$ Teresa Serés Seuma ${ }^{2}$}

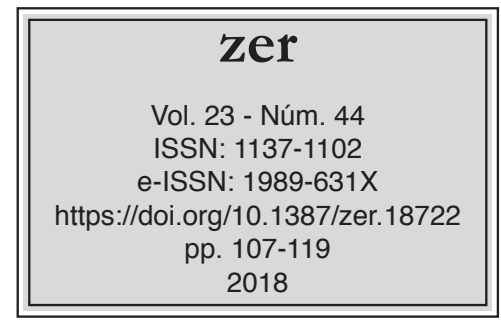

Recibido el 17 de noviembre de 2017, aceptado el 8 de marzo de 2018.

\section{Resumen}

Este estudio de la difusión mediática de un caso de pederastia descubierto en 2013 pretende mostrar cómo la información adopta diferentes formatos, como el ensayo o el serial radiofónico, y cómo cada uno puede aportar unas características específicas al relato original, expandiéndolo. El suceso primero fue cubierto por la prensa local. En 2016, Carles Porta publicó el ensayo Le llamaban padre, explicado a través de cuatro de sus principales implicados. Meses más tarde se narró la historia en un podcast, con los propios protagonistas explicando de forma serializada y con detalle las situaciones que vivieron y la investigación del caso.

Palabras clave: radio; multiplataforma; serialización; transmedia.

\section{Laburpena}

2013an antzemandako pederastia-kasu baten hedapen mediatikoari buruzko azterketa honen nahia da erakustea informazioak formatu ezberdinak hartzen dituela -esaterako, saiakera eta irrati-sail formatua-, eta haietako bakoitzak ezaugarri jakin batzuk eman diezazkiola

\footnotetext{
marionavisa@filcat.udl.cat - Universitat de Lleida

2 tseres@filcat.udl.cat - Universitat de Lleida
} 
jatorrizko kontakizunari, zabalduz. Tokiko prentsak egin zuen lehen gertaeraren jarraipena. 2016an, Carles Portak Le llamaban padre saiakera argitaratu zuen, gertaeran nahastutako lau pertsona nagusien azalpenekin. Handik hilabete batzuetara, istorioa podcast batean kontatu zen, eta protagonistek beraiek azaldu zuten, serializatuta eta xehetasunez, nola bizi izan zituzten gertaerak eta kasuaren ikerketa.

Gako-hitzak: irratia; multiplataforma; serializazioa; transmedia.

\begin{abstract}
This study of the media diffusion of a pedophile case discovered in 2013 aims to show how the information adopts different formats, such as the essay or the podcast 1 , and how each one can contribute with specific characteristics to the original story, expanding it. The event was first covered by the local press. Three years later, in 2016, Carles Porta published the essay Le llamaban padre, explained through four points of view. Months later the story was narrated in a podcast, with the protagonists explaining in a serialized and detailed way the situations they lived and the investigation of the case.
\end{abstract}

Keywords: radio; multimedia; serialization; transmedia. 


\section{Introducción, objetivos y metodología}

La convergencia digital y las narrativas transmedia permiten que en la actualidad los usuarios dispongan de múltiples y variados puntos de entrada al relato de los hechos, así como una mayor oportunidad de profundización e interacción. Las posibilidades de estas narrativas en la ficción han sido ampliamente estudiadas por, entre otros, Henry Jenkins (2006) y Carlos Scolari (2013). También cada vez se encuentran más casos de relatos periodísticos transmedia, que utilizan diversas plataformas para la cobertura de hechos noticiosos y cuentan con el rol activo de la audiencia a la hora de completar el relato. En este artículo nos centraremos en las narrativas transmedia de no-ficción, en las que según Irigaray (2015) podemos incluir los relatos periodísticos, las crónicas y los documentales en sus versiones multimedia, interactivas y transmedia, e incluso los relatos educativos.

A partir del estudio de la difusión mediática de un caso de pederastia descubierto en la localidad catalana de Castelldans en 2013, se pretende mostrar cómo la información -más allá de su presencia en los telediarios y los portales informativosadopta en la actualidad diferentes formatos, como el ensayo o el serial radiofónico, y cómo cada uno aporta unas características específicas al relato original, expandiéndolo. El suceso primero fue noticia cuando la policía detuvo a un educador social por abusos infligidos a los menores tutelados que tenía a su cargo. Tres años más tarde, en 2016, el periodista Carles Porta publicó el libro Le llamaban padre, explicado a través de cuatro de sus principales implicados. Meses más tarde se narró la historia en un podcast, con los propios protagonistas explicando de forma serializada y con detalle las situaciones que vivieron y la investigación del caso. Este podcast adapta el relato al formato sonoro, pero veremos que no se trata de un simple volcado de la información sino que se añaden diversos elementos y se tiene una mayor voluntad de implicar al usuario con su participación.

La metodología utilizada será el estudio de caso de la cobertura periodística local que se hizo en un primer momento, de las aportaciones del libro publicado por el periodista Carles Porta en 2016, y, finalmente, se enumerarán las características que la narración sonora del podcast añade al relato periodístico inicial. Este estudio será completado con entrevistas a tres de sus principales responsables: el autor Carles Porta, el director y realizador José Ángel Esteban y la responsable del proyecto Podium Podcast María Jesús Espinosa.

\section{Nuevas narrativas en la convergencia digital}

La convergencia digital ha sido definida como un proceso multidimensional que, facilitado por la implantación generalizada de las tecnologías digitales de telecomunicación, afecta al ámbito tecnológico, empresarial, profesional y editorial de los medios de comunicación, propiciando una integración de herramientas, espacios, métodos de trabajo y lenguajes anteriormente disgregados, de forma que los periodistas elaboran contenidos que se distribuyen a través de múltiples plataformas, mediante los lenguajes propios de cada una (García Avilés, Salaverría, 2008: 5).

Así, el periodismo ha podido adoptar nuevas formas, narrando los hechos de actualidad por distintos medios, soportes y plataformas. Rost (2016) describe tres formas 
distintas de periodismo según su grado de expansión e interacción del espectador: periodismo multiplataforma, periodismo crossmedia y periodismo transmedia.

En el periodismo multiplataforma el relato se adapta o se vuelca en diferentes plataformas, pero sin que se genere nuevo contenido ni se exploren las posibilidades que ofrece el nuevo medio. En el periodismo crossmedia se narra un hecho de actualidad a través de distintos medios, soportes y plataformas, siendo cada mensaje independiente y haciendo una contribución a la historia global. No hay participación activa de los usuarios en la construcción de contenidos; sino que en el mejor de los casos, intervienen como receptores interactivos, que consumen y/o propagan la historia. Finalmente, el periodismo transmedia es una forma de narrar un hecho de actualidad que se vale de distintos medios, soportes y plataformas, donde cada mensaje tiene autonomía y expande el universo informativo, y los usuarios contribuyen activamente a la construcción de la historia (Rost, 2016: 15).

La narrativa transmedia fue definida inicialmente por Henry Jenkins (2003), y aporta este plus más a la narrativa multiplataforma o crossmedia, ya que se caracteriza por ser un relato que se despliega en múltiples medios y plataformas, cada una aportando aquello que mejor puede, y en el cual una parte de los consumidores asume un rol activo para expandir la historia (Scolari, 2013: 46). Estas múltiples plataformas pueden incluir desde películas, series televisivas, novelas, flash mobs, aplicaciones para dispositivos móviles, sitios web, obras de teatro, cómics, conciertos, eventos en directo, videojuegos, plataformas web 2.0 o, cómo en el caso que nos ocupa, podcast.

La expansión del relato en múltiples plataformas y la interacción y creación de contenidos por parte del usuario se ha explorado ampliamente en proyectos de ficción, pero también tiene cabida en relatos de entretenimiento y periodísticos, ya que permite una mayor profundización e interacción con el usuario, en comparación con otros géneros más vinculados a la estricta actualidad. El formato webdoc, por ejemplo, ha sido uno de los pioneros en la narración de contenidos periodísticos con un formato más extendido e interactivo, incorporando al documental tradicional nuevas posibilidades como la libre navegación y una mayor conversación con la audiencia (Gifreu, 2013).

En una expansión transmedia, cada plataforma aporta sus características más destacadas y ofrece unas posibilidades de las que carecen otros medios. Así, como apunta Larrondo (2016), las principales claves del éxito de estas narraciones reside en explorar las características expresivas de los distintos medios para observar cuáles son las funciones que aportan a la historia y que pueden ser tan distintas cómo centrarse en informar, en relatar, en resumir, en generar expectativas, en compartir, en hacer participar... y en un largo etcétera de posibilidades para expandir el relato desde diferentes ópticas.

\section{La serialización de contenidos periodísticos: del folletín al podcast}

La crónica de sucesos existe desde la antigüedad y desde el siglo XIX se ha narrado de forma serializada en periódicos. Aunque para numerosos académicos los inicios de la literatura de no-ficción o novela-reportaje (Cantavella, 2002) se remontan al año 1965, cuando Truman Capote publicó A sangre fría a partir de los relatos que había escrito en el New Yorker sobre un crimen cometido en Kansas, ya se encuentran 
ejemplos parecidos de décadas anteriores. Entre 1889 y 1940 fue muy popular el cronista de sucesos escocés William Roughead, que atendía los juicios de asesinatos más importantes y los cubría por entregas en el Juridical Review, un periódico mensual sobre temas legales, y que posteriormente recogió en diversas antologías. También el americano Edmund Pearson publicaba en revistas crónicas criminales, que después recopiló en libros como Studies in Murder (1924).

Se trata por tanto de un género híbrido entre la literatura y el periodismo y que en numerosas ocasiones serializa la cobertura de un suceso real. Actualmente, en un momento en que el periodismo digital se caracteriza mayoritariamente por versar sobre la actualización de noticias con escasa profundización, el documental serial radiofónico o televisivo sobre hechos reales criminales (conocido como True Crime), así como el ensayo periodístico, ofrece una aproximación más rigurosa y completa a la comprensión de los hechos y goza de gran popularidad. En televisión, los casos de The Staircase (Maha productions 2004-), The jinx (HBO 2015-) Making a Murderer (Netflix, 2015-) o el nacional Muerte en León (Movistar +. 2016) son un ejemplo del interés por este formato. En radio, el podcast Serial (Sarah Koenig, 2014), que en su primera temporada describe un caso de asesinato cometido en 1999, tuvo una audiencia media de 1'5 millones de personas, se erige como precedente claro del proyecto que aquí estudiamos.

Todas las citadas son obras que relatan historias criminales reales con un lenguaje propio de la ficción. Así, a partir de testimonios reales y de imágenes de archivo, los realizadores cuentan, a menudo en primera persona, unos hechos que conocen de primera mano y de los que proporcionan todos los detalles posibles. Serial, conducido por la periodista Sarah Koenig, ofrecía al espectador todas las claves para poder comprender el caso, con entrevistas a las personas involucradas, conversaciones telefónicas con el imputado, interrogatorios llevados a cabo en las dependencias de la policía y declaraciones de los abogados y testigos en el juicio. El formato serial permitió profundizar en cada elemento del caso con detenimiento y ofrecer distintas pruebas que iban generando la necesidad de saber más de la historia. (Linares de Palomar, Neira, 2017). De esta manera, al tener tantos datos específicos y tantos puntos de vista relativos a la investigación del caso, el espectador asiste durante varias horas a la disección de los hechos, y a menudo tiene la percepción de asistir a los acontecimientos que se relatan.

Por tanto, se confirma en parte la consideración del pensador y periodista Ignacio Ramonet (2002: 51-52), según el cual el periodismo había sido históricamente una organización triangular resultante de la relación entre el acontecimiento, el mediador (que la analizaba) y el ciudadano; y que en cambio actualmente se ha convertido en un eje en uno de los extremos del cual está el ciudadano y en el otro el acontecimiento. Pero en los casos citados y en el que aquí analizamos, la presencia del periodista que guía el relato o la participación de expertos, ayuda a contextualizar los hechos, que son descritos desde muchos prismas, Y al final, eso sí, es el espectador quien también puede formarse su propio juicio a partir de los hechos expuestos.

En el caso del serial radiofónico, los últimos proyectos en este sentido se han beneficiado de los cambios producidos por la digitalización, ya que ésta permite la difusión del contenido más allá de la programación habitual de las emisoras tradicionales, a través de podcast que permiten profundizar más en ciertos temas. Por sus 
características de escucha no sincrónica, el podcast permite explorar contenidos no estrictamente vinculados con la actualidad.

Técnicamente el podcasting es posible gracias a la tecnología digital, en concreto la compresión en MP3, y al RSS, con lo que se pueden distribuir archivos de audio comprimido a aquellas personas que se han suscrito a un agregador. Una vez recibido, el archivo puede escucharse tanto en equipos estables como en reproductores portátiles o teléfonos móviles. Así como la digitalización y popularización de música online gracias a archivos comprimidos cambió radicalmente el negocio de la industria musical (Roig,A; San Cornelio, G; 2015), el podcasting también lo hizo con el medio radiofónico, ya que actúa como "un servicio útil que mejora la distribución y la relación personalizada entre el emisor y el oyente" (Gallego, 2010: 9). Y este cambio no afecta sólo a cuestiones tecnológicas, sino también a la narrativa sonora y a la relación emisión-recepción y lo que ello implica a la hora de construir el relato en sí mismo (McHugh, 2016). Como afirman Videla y Piñeiro (2017), Internet y, más concretamente, las plataformas sociales proveen a la radio de un escenario idóneo para multiplicar los puntos de contacto con los oyentes-usuarios y generar nuevas dinámicas de interacción-participación que hacen volubles e intercambiables los roles de emisor-receptor

Actualmente, en nuestro país se vive una etapa de apuesta por esta narrativa sonora. En 2016 se creó Podium Podcast, del grupo Prisa, que como se define en su sitio web "es una red viva y flexible con una oferta a la carta que se adapta a las necesidades, gustos e intereses de cada oyente. Son productos pensados exclusivamente para Internet con nuevas narrativas radiofónicas que cuida el sonido y apuesta por la calidad." Al servicio de escucha de capítulos, se añade a menudo una página propia del programa dónde se puede encontrar información adicional, imágenes relacionadas y posibilidades de interacción con el contenido, como también hizo Serial, que supo aprovechar los huecos entre episodios colgando material gráfico en su página web, en la que se dejaba espacio para los comentarios de los oyentes. Así, estas plataformas multiplican las vías de participación de los oyentes y potencian el clima de comunidad (Peña y Pascual, 2013).

Lance Dann (2014) apuntó cómo el podcast posibilita crear narrativas más extensas y la creación de un mundo transmedia alrededor, ya que el formato a través del cual se distribuye es una clara invitación a que el espectador añada su experiencia al relato original. García Marín, en su trabajo final de Master sobre el podcast y su uso actual (2016) habla de cómo la hibridación de lenguajes y la utilización de distintos espacios para propagar los relatos desborda la definición clásica del podcasting como un medio exclusivamente sonoro y se adentra en el terreno del podcasting transmedia. Este autor introduce el término transcasting para hacer referencia a aquellos proyectos mediáticos que, teniendo al podcast como medio seminal, extienden y dispersan su narrativa utilizando diversas textualidades y amplían su entorno comunicativo a otras plataformas, medios y lenguajes, presentando una clara textura transmedia.

\section{Estudio de caso: Le llamaban padre}

Este estudio de caso de la cobertura mediática del suceso narrado en Le llamaban padre se centra en analizar las aportaciones estilísticas y narrativas que cada medio 
(prensa, ensayo periodístico y finalmente el propio podcast documental) aportan al relato original, así como en ver en qué forma han sido utilizadas las características propias de la transmedialidad, como la expansión de los contenidos y la participación de la audiencia.

\subsection{Cobertura periodística en el diario Segre}

En este apartado describiremos cómo fue la cobertura del caso en el diario comarcal Segre, que fue el primero en informar del suceso e hizo un seguimiento de éste durante todo el mes de julio de 2013. Al tratarse de un periódico de proximidad, nos interesa saber también qué elementos caracterizaron su cobertura y cuáles fueron sus principales fuentes de información.

El análisis de las piezas informativas publicadas durante el mes de julio de 2013 se hace desde la perspectiva de la teoría del establecimiento de la agenda (McCombs y Shaw, 1972). y la teoría del framing (Bateson, 1972), según las cuales la percepción de los asuntos sociales está condicionada en gran medida por la mayor o menor representación que se hace de éstos en los medios de comunicación, y que éstos no se limitan tan solo a visibilizar ciertos temas por encima de otros, sino que también nos dan el marco conceptual -frame- debajo del cual hemos de interpretarlos.

El pederasta acusado de abusar de menores en un piso de acogida en Castelldans fue detenido un 27 de junio, aunque los hechos no aparecieron en la prensa hasta el 5 de julio. Durante este mes fueron 19 los artículos publicados al respecto en el Segre de los que se ha realizado un análisis de contenido para observar la fecha de publicación, la ubicación dentro del periódico, el contexto de la página, el género, la presencia de fotografías, la utilización o no de la presunción de inocencia y las fuentes utilizadas para redactar la noticia.

El caso fue portada en seis ocasiones, aunque no desde el primer día, sino que empezó a aparecer de forma breve en la portada a partir del segundo día de seguimiento del caso. No fue destacado como noticia principal hasta la publicación de las declaraciones de la entonces consejera de Benestar Social i familia, Neus Munté, en las que dudaba si se habían cometido errores al asignar menores a este educador.

El género de las noticias es el artículo, a excepción de un reportaje sobre el estado de la acogida de menores tutelados, publicado a finales del mes, en el que se daban claves para la interpretación del suceso a partir de entrevistas a diferentes psicólogos y familias de acogida.

Por lo que se refiere a las fotografías, durante los cinco primeros días se utilizan imágenes de archivo de la localidad de Castelldans o de los Mossos d'Esquadra. El rostro del pederasta no aparece hasta el día 13 de julio, y aparece directamente en la portada. Después, sigue apareciendo hasta en cinco ocasiones.

En los titulares y el cuerpo de la noticia se respeta siempre la presunción de inocencia y el tratamiento informativo se destina, una vez se ha informado del caso, a cuestionar el papel de la conserjería de Benestar Social i familia en el seguimiento del caso y en recoger las declaraciones de fuentes de la Generalitat (11 noticias). De las otras, cinco se destinan a describir cómo se destapó el caso o a las acciones realizadas por el pederasta con los niños que tuvo a cargo desde 1997.

De las 19 noticias, 9 contienen fuentes policiales, 8 de la Generalitat, 5 de instituciones judiciales, 2 de la Fiscalía de menores, 2 del alcalde de Castelldans, 3 de 
la Federació d'Associacions de Famílies Acollidores de Catalunya (CAFAC) y una del Síndic de Greuges. En ningún caso se encuentran testimonios directos de las víctimas ni del pederasta ni de la Fundanción Juvanteny (que enviaba a los niños a la casa de acogida), que según el diario se negó a hacer declaraciones al menos en dos ocasiones.

Aparte de las noticias, el caso aparece durante el mes de julio dos veces en el espacio de la contraportada, con un signo negativo para la consejera.

Para completar la información que se obtuvo de los medios locales durante el mes de la detención cabe mencionar que el quincenal comarcal Som Garrigues aportó información muy discreta sobre el caso, ya que voluntariamente se optó por publicar tan sólo la información de la detención, a causa de la imposibilidad de hacer un seguimiento a fondo del caso por falta de medios y personal durante las vacaciones. En el número que abarca del 19 de julio al 1de agosto, en la página 12 se informa de "A presó un educador social per possessió de pornografia infantil" ("A la cárcel un educador social por posesión de pornografía infantil"). Se respeta la presunción de inocencia y las fuentes para realizar la noticia son, según se específica en el artículo, la Agencia Catalana de Noticias, el canal 324 y el diario Segre.

A pesar de que en este último quincenal, por proximidad, la cobertura hubiera podido ser mayor, encontramos en estos periódicos comarcales y locales rigurosidad a la hora de hablar del entonces presunto pederasta y en la contención de sensacionalismo aplicada al caso. No fue así en otros periódicos de ámbito autonómico o nacional, ya que, por citar algunos ejemplos, La Vanguardia tituló la noticia, el día 28 de septiembre de 2013 con un "La habitación del horror" y el Ara, el día 27, con un "El pederasta de Castelldans havia muntat una "casa dels horrors" per abusar dels menors i filmar-los" ("El pederasta de Castelldans había montado una "casa de los horrores" para abusar de menores y filmarlos"), titular que además no guarda la presunción de inocencia del pederasta. Tampoco El Periódico la respetó el 13 de julio: "Els Mossos pensen que un acollit va ajudar el pederasta a atraure nens" ("Los Mossos piensan que un acogido ayudó al pederasta a atraer niños"). Se reprodujo, así, por parte de algunos periódicos y, sobre todo, de algunas televisiones privadas, la estigmatización que ya había ocurrido en informar sobre otros casos similares como el caso Raval (acontecido en 1997 y cuya cobertura ha sido analizada por González Jiménez en 2014).

\subsection{Libro Le llamaban padre, de Carles Porta}

El periodista Carles Porta era conocido antes de la publicación de Le llamaban padre por haber cubierto otros sucesos criminales en documentales (Tor, la muntanya maleïda; TV3, 1997) o ensayos periodísticos (Tor, tretze cases $i$ tres morts, 2005; Fago, 2012). Cuando se descubrió el caso de pederastia de Castelldans, Porta se interesó por los detalles de éste, ya que era amigo del Mosso al cargo de la investigación. Y así empezó a involucrarse en el caso hasta acabar entrevistando a sus principales protagonistas.

El acercamiento periodístico a un suceso tiempo después de haber ocurrido y cuando ya no recibe el foco mediático es habitual en el mundo del periodismo narrativo. Aparte del caso citado de Truman Capote, se encuentran casos similares al 
que nos ocupa por su temática, como el libro Raval. Del amor a los niños (Arcadi Espada, 2000), a raíz del caso de pederastia descubierto en el barrio del Raval de Barcelona en 1997, y el posterior documental De nens (Joaquim Jordá, 2003). Este libro y documental, con la perspectiva que permite la distancia y una mayor contextualización, añaden nuevas perspectivas al caso a las dadas por los periódicos durante el descubrimiento de los hechos. En ambos se denuncia la manipulación policial y judicial que hubo detrás de la difusión del caso y los intereses urbanísticos para cambiar el barrio del Raval.

El documental Capturing the Friedmans (2007), de Andrew Jarecki, también se acerca a un caso de pederastia acontecido años antes, en este caso finales de los 80 , centrándose en las consecuencias que sufren años después las víctimas y también los acusados.

En el libro Le llamaban padre, Premio Godó de reporterismo y ensayo periodístico 2015, Porta se aproxima a los hechos, tan difíciles de comprender, a partir del relato de sus principales protagonistas. Porta desaparece como narrador en el libro y se centra en ordenar los testimonios de quienes vivieron los hechos, que se cuentan en primera persona. Accedemos al relato en voz propia del policía que descubrió el caso, de la víctima principal, del pederasta y de la responsable de la organización que enviaba los niños al acusado. Cuatro voces que, a excepción de la policial, nunca fueron recogidas en el seguimiento del caso por parte de los periódicos.

Solo en los agradecimientos aparece la voz de Carles Porta para matizar unas palabras del pederasta y es el único momento en que da su opinión sobre los hechos que ha narrado: que el acusado cometió el peor crimen del mundo, robar la inocencia de los niños que le llamaban padre.

\subsection{Le llamaban padre, de Podium Podcast}

Le llamaban padre es una narración sonora creada por Podium Podcast, que cuenta con 7 episodios de 20 minutos cada uno sobre, como se indicó en la promoción, uno de los casos de pederastia mejor documentados de nuestro país. El equipo que estuvo al cargo de esta creación está formado por Carles Porta en la dirección y guion; José Ángel Esteban en la dirección, guion y diseño de sonido; Iñigo Guerrero en la edición y mezcla de sonido; Guillem Arnal en la toma de sonido y Laia Gil y Óscar Rodríguez en la producción. En 2017, este proyecto recibió una mención especial en los Premios de Periodismo Ortega y Gasset 2017.

Los siete capítulos que forman parte del podcast son: Una frase en Facebook, La habitación de arriba, Cintas de vídeo y cenizas, La perfección de la perversión, Un flash y una película de terror, El famoso David y Un secreto entre nosotros. Carles Porta aparece como narrador en todos los capítulos, hecho que interpela al oyente y lo atrapa en el relato.

A diferencia del libro, además de esta mayor presencia del narrador, en los podcast los testimonios no se separan en diferentes capítulos, sino que se reconstruye la historia en orden cronológico. Y una de las principales aportaciones de este documental es la oportunidad de escuchar estas explicaciones de la propia voz de sus protagonistas, ya que Carles Porta contaba con los testimonios orales de los implicados. Y los elementos añadidos a la narración, como los efectos sonoros, ayudan a contextualizar 
la historia y hacer sentir al oyente inmerso en el relato. Mientras escuchamos a los protagonistas, el sonido de un campo de fútbol, del teclado de un ordenador, el de una caja registradora o el sonido de un timbre nos transportan a la acción. Y el silencio. Porque en esta historia también hubo muchos tiempos de espera, que con el silencio y el montaje respetando diferentes niveles de audio, permiten transmitir la tensión del momento, así como el desarrollo, en ocasiones, de acciones simultáneas.

El potencial de la radio o el podcast se utiliza así de la mejor manera para completar la historia, recreando su universo sonoro y con las explicaciones directas de sus protagonistas. Y se construye un relato diferente al de libro, como es propio de una narración transmedia. Según apunta José Ángel Esteban, se quería hacer algo completamente diferente, en parte por las características propias del medio y en parte porque se añadieron muchos elementos nuevos que completaron el relato. Por ejemplo, en el capítulo final se pregunta a la víctima si, tal como señalan muchas estadísticas, cree en la posibilidad de convertirse él en abusador, cuestión que no se aborda en el libro.

El podcast contiene, aparte de los siete capítulos, otros elementos que expanden el proyecto y acompañan al oyente en su escucha. Se trata de los "Así se hizo", que se emitían un día después del capítulo y explicaban el proceso de elaboración del podcast. Según apunta María Jesús Espinosa "la estrategia transmedia es uno de los pilares esenciales de Podium Podcast. Nos parecía interesante contar ese otro relato que estaba detrás del relato principal." Por lo que respecta a los extras, "se trataba de saber cómo había sido el proceso que había realizado Carles y, al mismo tiempo, conocer cómo se estaba traduciendo del lenguaje escrito al sonoro."

A parte de estas narraciones, en la página de Podium Podcast se podía acceder también a materiales extra, como una línea de tiempo del caso, una carta extraída del sumario, que también está en el libro, o un fragmento inédito de la sentencia. Todo este material extra no se encuentra en una web propia del proyecto, sino que se accede a él a través de una pestaña llamada blog.

Los capítulos se difundieron en las redes sociales Facebook y Twitter propias del proyecto y las de la plataforma. La página de Facebook de Le llamaban padre ya no se encuentra disponible, ya que se retiró al finalizar el podcast, pero durante su difusión tuvo una buena acogida. Por la temática de la obra, no se realizaron operaciones para animar la conversación, sino que se planteó más como una red de acompañamiento en la escucha. Como comenta Espinosa: "todas las redes sociales de los diferentes productos de Podium tienen su propia estrategia en redes sociales. En este caso, sabíamos que debíamos ir con cuidado, puesto que estábamos manejando un material muy sensible, de manera que la función esencial de las redes era la de acompañar al oyente a lo largo de los siete episodios para que sintiera la tensión y el suspense del caso." En la página oficial de Podium Podcast, que sí sigue en activo y cuenta con 5687 seguidores en noviembre de 2017, se puede ver como las veces en que se promociona el proyecto se advierte de la dureza de la serie.

En Twitter, con 7196 seguidores, se realizó una operación similar, con más oportunidad, eso sí, de interactuar con los creadores, a los que se mencionaba en numerosos tuits de felicitación.

Finalmente, es muy importante señalar que, como comenta Carles Porta algunas víctimas de pederastia han denunciado abusos después de leer el libro y -sobre todo- 
escuchar el podcast. Se está utilizando también el material en cursos de pediatría, en centros de prevención de abusos o en terapias para superarlos. Este logro final de un proyecto que acerca la realidad de las víctimas y del abusador a la audiencia, en un tema tan complicado como la pederastia, demuestra que un buen relato de los hechos siempre tiene un largo recorrido y un impacto positivo en la audiencia.

\section{Conclusiones}

En este estudio hemos visto cómo las nuevas formas de narrar los hechos periodísticos enriquecen la comprensión de éstos, aprovechando las características propias de cada medio para contar el relato. En el caso del podcast Le llamaban padre podemos definir claramente que se trata de una narrativa que complementa un formato anterior (el libro) con algunos elementos transmedia cómo la expansión del relato, aunque en este caso, por la naturaleza del tema, no se ha hecho muy partícipe al público ni se ha motivado que asuma un rol muy activo en lnternet, más allá de la posibilidad de compartir los capítulos y hacer comentarios.

Según la terminología de Rost citada al principio del artículo, para que una narrativa sea transmedia resulta fundamental la intervención de los usuarios para expandir el mundo narrativo. Y no sólo una participación que él llama "selectiva" -que incluye el control del proceso de recepción-sino una interactividad "comunicativa", que incluya posibilidades de expresión y comunicación para los usuarios, que puedan hacerse públicas dentro de la historia narrada (Rost, 2016: 17). En el podcast analizado sí se favorece la interactividad del usuario, desde la más "selectiva" como la personalización de la escucha a la más "comunicativa" como la posibilidad de compartir el capítulo o de hacer comentarios en las redes sociales propias o del programa. Y, como se ha comentado, su uso en prevención de abusos o en terapias para superarlos, demuestra también como el proyecto interacciona con los oyentes y ha servido para facilitar la conversación en ámbitos propicios sobre un tema muy a menudo silenciado.

El podcast sobre un suceso informativo da por tanto una mayor oportunidad de profundizar en los hechos, igual que en su momento hizo el libro, ya que su modo de difusión asincrónico y su escucha mayormente individual permite explorar temas más allá de la estricta actualidad y más especializados. A su vez, el formato serial permite explicar con detalle y diferentes puntos de vista cada suceso, con la incorporación de numerosas fuentes. El relato únicamente sonoro también facilita la obtención de testimonios, sobre todo respecto a temas criminales. Se puede configurar así un relato más polifónico, que define al podcast como un formato idóneo para el periodismo de investigación. 


\section{Referencias bibliográficas}

Bateson, G. (1972). The logical categories of learning and communication. Steps to an Ecology of Mind: Collected Essays in Anthropology, Psychiatry, Evolution, and Epistemology, 279-308.

Cantavella, J. (2002). La novela sin ficción: cuando el periodismo y la narrativa se dan la mano. Oviedo: Septem ediciones.

Dann, Lance. (2014) Only half the story: Radio drama, online audio and transmedia storytelling. Radio Journal: International Studies in Broadcast \& Audio Media, 12(1-2), 141-154.

Gallego, J. I. (2010). Podcasting. Nuevos modelos de distribución para los contenidos sonoros. Vol. 17. Barcelona: Editorial UOC.

García Marín, D. (2016). Podcasting y transmedia: el transcasting. Trabajo Final de Máster: Universidad Nacional de Educación a Distancia.

Gifreu, A. (2013). El documental interactivo. Evolución, caracterización y perspectivas de desarrollo. Barcelona: Editorial UOC.

González Jiménez, A. P. (2014). Periodismo de sucesos y documental reflexivo: cobertura mediática y puesta en pantalla del Caso Raval. Máster Universitario en Comunicación y Cultura de la Universidad de Sevilla

Irigaray, F., \& Lovato, A. (2015). Producciones transmedia de no ficción. Análisis, experiencias y tecnologías. Rosario: Editorial de la Universidad Nacional de Rosario

Jenkins, H. (2006). Convergence culture: Where old and new media collide. NYU press.

Larrondo, A. (2016). El relato transmedia y su significación en el periodismo. Una aproximación conceptual y práctica. Trípodos 38, 31-47. Recuperado de http://www. tripodos.com/index.php/Facultat_Comunicacio_Blanquerna/article/view/324/137

Linares de Palomar, R.; Neira, E. (2017). Serial, el Programa Radiofónico que Resucitó el Podcasting. Area Abierta, 17(1), 73-82. Recuperado de http://dx.doi. org/10.5209/ARAB.53356

McCombs M. E.; Shaw, D. (1972). The agenda-setting function of mass media. $\mathrm{Pu}$ blic opinion quarterly, 36(2), 176-187.

McHugh, S. (2016). How podcasting is changing the audio storytelling genre. Radio Journal: International Studies in Broadcast \& Audio Media, 14(1), 65-82.

Peña, P.; Pascual, A. (2013). Redes sociales en la radio española. Facebook, Twitter y Community Management. Zer. Revista de Estudios de Comunicación, 18(35). Recuperado de http://www.ehu.eus/ojs/index.php/Zer/article/view/10677

Ramonet, I; Albiñana, A. (2002). La tiranía de la comunicación. Barcelona: Debate. Roig, A; San Cornelio, G. (2015). Being Lucky. Transmedia and Co-Creation Practices in Music Video-Clips. International Journal of Transmedia Literacy (IJTL). 1.1 December 2015.

Rost, A., Bernardi, M. T., \& Bergero, F. (2016). Periodismo transmedia, la narración distribuida de la noticia. Río Negro, Argentina: Publifadecs.

Salaverría, R.; García-Avilés, J. A. (2008). La convergencia tecnológica en los medios de comunicación: retos para el periodismo. Trípodos, 23, 31-47. Recuperado de http://www.raco.cat/index.php/TRIPODOS/article/viewFile/118910/154114

Scolari, C. A. (2013). Narrativas transmedia: cuando todos los medios cuentan. Bilbao: Deusto S.A. Ediciones. 
Videla-Rodríguez, J. J., \& Piñeiro-Otero, T. (2017). La radio online y offline desde la perspectiva de sus oyentes-usuarios. Hacia un consumo híbrido. Estudios sobre el Mensaje Periodístico, 23(2), 1437-1455. 